\title{
Body mass index and waist circumference documentation in Canadian primary care electronic medical records
}

Cliff Lindeman ( $\sim$ clindema@ualberta.ca)

University of Alberta Department of Resource Economics and Environmental Sociology https://orcid.org/0000-0003-2851-265X

Allyson Jones

University of Alberta

Michael Cummings

University of Alberta

Anh N. Q. Pham

University of Alberta

Carla RD, PhD Prado

University of Alberta

John C. Spence

University of Alberta

Neil Drummond

University of Alberta

\section{Research article}

Keywords: Waist circumference, body mass index, electronic medical records, primary care

Posted Date: July 14th, 2020

DOl: https://doi.org/10.21203/rs.3.rs-41280/v1

License: (a) (1) This work is licensed under a Creative Commons Attribution 4.0 International License. Read Full License 


\section{Abstract}

Background: Electronic medical records (EMR) are commonly used in primary care to document patient measurements including height and weight that are then used to produce body mass index (BMI) scores. However, little is known about the proportion of waist circumference (WC) documentation compared to $\mathrm{BMI}$ and the characteristics of patients with these measures. This study used a pan-Canadian research database, sourced from primary care EMRs, to describe BMI and WC documentation in primary care.

Methods: A retrospective cohort design of primary care providers participating in the Canadian Primary Care Sentinel Surveillance Network (CPCSSN), this study presented descriptive, observational findings of EMR inputs. Frequencies and percentages of median BMI and WC documentation in CPCSSN EMRs and patient demographic characteristics are compared.

Results: Of 707,819 Canadian patients aged of 40 or older, at least one BMI input was recorded for $58.6 \%$ and $11.5 \%$ had WC notations. The majority of patients $(98.1 \%)$ with at least one WC measurement also had a BMI measurement while conversely $19.2 \%$ of patients with at least one BMI measurement also had a WC measurement. The most common median BMI category was overweight (36.9\%) and median WC was 95.0 centimetres $(\mathrm{IQR}=21.5)$.

Conclusions: This study reports the documentation of obesity and overweight in select Canadian primary care EMRs infrequently recorded WC when compared to BMI. Future studies should examine the frequency and categories of anthropometric measurements in people with commonly managed chronic conditions and whether BMI and WC inputs are missing at random.

Trial registration: Not applicable for this study.

\section{Background}

As of $2016,84.2 \%$ of Canadians were attached to a primary care provider (1), who commonly manage many chronic conditions (2) whose risk factors relate to being obese or overweight. The medical determination of obesity and being overweight is estimated by body mass index (BMI) and/or waist circumference (WC). These measurements provide an empirical value to describe and compare a patient's size and weight distribution, which can then be recorded and tracked in electronic medical records (EMRs).

The Canadian Primary Care Sentinel Surveillance Network (CPCSSN) is the first pan-Canadian platform for chronic disease surveillance in primary care settings (3). The CPCSSN collects data from nearly two million Canadians across eight provinces and territories and 12 different EMR systems (3). The data CPCSSN collects includes billing, patient demographic characteristics, problem list, and measurements such as weights and heights (3). Previous studies have examined CPCSSN data to estimate the prevalence of obesity in primary care but noted that WC was infrequently documented; but did not compare patient BMI category by WC category nor did they describe the demographic characteristics of 
patients who have WC documented (4). To the author's knowledge, there are no descriptions of BMI and WC measurements across multiple primary care EMR systems in the Canadian health system.

The objective of this study was to analyze a large data set of Canadian primary care EMR data to report on the frequency of notations related to obesity and being overweight as designated by $\mathrm{BMI}$ and WC categories by patient demographic characteristics.

\section{Methods}

This study uses a retrospective cohort design. Since 2008, CPCSSN has used extracted EMR data to create a longitudinal data set that is stored in a secure, de-identified, data repository for epidemiological surveillance studies and quality improvement initiatives. The information is sourced from nearly 1,400 primary care providers across eight provinces and territories who care for nearly two million Canadians (3).

All patients were over the age of 40y as of December 1, 2018 as of the 2017 CPCSSN national data set; median BMI values outside of 10 to $80 \mathrm{~kg} / \mathrm{m}^{2}$ and median WC values outside 30 to 200 centimeters were excluded and assumed to be data entry errors. This descriptive analysis employed complete-case analysis: patients' data had to include sex, age, postal code (first three digits), and those who had at least one visit with a CPCSSN primary care provider between January 1, 1990 and December 31, 2017.

The analysis employed frequencies and percentages of measurement by BMI category (5) and WC category (5) by sex. Patient demographic characteristics are presented by measurement frequency.

The University of Alberta Research Ethics Office approved this study (Pro00056753).

\section{Results}

In total, 707,819 patients had sex, age, and postal code data recorded in their EMRs. This cohort was $18.7 \%$ rural; however, those with at least one record of BMI (18.3\%) or WC $(15.9 \%)$ were notably less rural. Nearly one out of every ten (11.5\%) of the total number of patients had at least one WC measurement; $58.6 \%$ of patients had at least one BMI measurement. The majority of patients (98.1\%) with at least one WC measurement also had a BMI measurement, while $19.2 \%$ of patients with at least one BMI measurement also had a WC measurement (Table 1).

The median BMI in the cohort was $27.7(\mathrm{IQR}=7.5)$, with the most common median BMI category was overweight (36.9\%) (Table 2). The median WC was 95.0 centimetres $(I Q R=21.5)$, more males were in the smaller WC category (52.2\%) while more females were in the larger WC category (55.1\%) (Table 3$)$.

Patients with at least one BMI and WC measurement were tabulated (Table 4). Most males with a WC >=102 cm had a median category of obese (70.5\%) (class IIII), compared to $57.1 \%$ of females with a WC 
$>88 \mathrm{~cm}$. WC measurements were mostly $(84.5 \%)$ conducted for patients with median 'normal' BMI to mild (class I) obesity.

\section{Discussion}

Documentation of BMI by primary care providers was found to be a more commonly recorded measure than WC in EMRs. Based on BMI alone, the proportion of overweight or obese patients in our analysis was $71.7 \%$ (82.9\% males and $67.2 \%$ females) which approximates the projection of BMl categories published by Statistics Canada ( $69.4 \%$ of adult Canadians aged 18 and older) (6); albeit our cohort included patients at least 40 years of age. The proportion of patients without at least one BMI $(293,051$ or $41.4 \%$ of the included cohort) may be due to patients in the underweight or normal weight levels having no BMI recording in primary care EMRs (7). Future studies should investigate missing not-at-random BMI and WC EMR inputs (8).

We found 170 males and 1,710 females with a documented median BMI in the normal category and a high category (median) WC, this may be due to the differing WC categories, which are 88 centimetres for woman and 101 centimetres for men. Another possibility is that either the BMI and/or the WC values were inputted incorrectly.

The magnitude of difference between the proportion of WC measurements compared to $\mathrm{BMI}$ measures was surprising. Our results indicate that it is uncommon for a primary care provider to record WC if a BMI is indicated as outlined (see Table 1). Measuring WC is a simple and time efficient measurement and should be used in concert with BMI to gain a better understanding of weight in relation to height and an approximation of weight distribution. Not measuring WC may result in misidentifying individuals who could benefit from future interventions (9).

Several limitations are acknowledged for this study. First, EMR data is extracted from voluntarily participating CPCSSN 'sentinels', who collectively care for a small proportion ( 5\%) of the Canadian population (10). Second, although CPCSSN diligently works to standardize EMR data from multiple EMR systems, data may be absent from EMR fields that are not included in CPCSSN data holdings, such as Subjective, Objective, Assessment, and Plan (SOAP) notes. Finally, the analysis was limited to what providers measure and then subsequently record in their EMR.

Future studies should explore the documentation of BMI and WC by chronic conditions commonly managed in primary care through tools such as the Edmonton Obesity Staging System, which categorizes patients by BMI level and stage of chronic condition (11). This would provide needed context for BMI category and chronic condition severity.

\section{Conclusion}

This study reports the documentation of body size estimates in select Canadian primary care EMRs were infrequently recorded, especially WC. Although it may be useful to track baseline and changes in weight, 
$\mathrm{BMI}$ alone does not describe the distribution of weight, which is correlated with chronic conditions.

Several suggestions are made that require further research to improve the understanding of anthropometric documentation in primary care EMRs.

\section{Declarations}

Research ethics approval was obtained by the University of Alberta: (Pro00056753).

\section{Consent for Publication}

Not applicable.

\section{Competing Interests}

The authors have no conflicts of interest to disclose.

\section{Funding}

No funding was received to support this project. Therefore, no sponsor was involved in any aspect of the review.

\section{Authors Contributions}

$\mathrm{CL}, \mathrm{AJ}, \mathrm{MC}, \mathrm{CP}, \mathrm{AP}$, and ND formulated the project idea and developed the study methods; AJ and ND acquired the data; and all authors have read and approve the manuscript.

\section{Availability of Data and Materials}

The CPCSSN data generated from this study is not available for general release. In order to access the data, approval from the CPCSSN Surveillance Research Standing Committee is needed as well as research ethics approval.

\section{Abbreviations}

$\mathrm{BMI}=$ body mass index

CPCSSN = Canadian Primary Care Sentinel Surveillance Network

$\mathrm{EMR}=$ electronic medical records

$\mathrm{SD}=$ Standard deviation

SOAP = Subjective, Objective, Assessment, and Plan

$\mathrm{WC}=$ waist circumference 


\section{References}

1. Statistics Canada. (2017). Primary Health Care Providers. Retrieved from: https://www150.statcan.gc.ca/n1/pub/82-625-x/2017001/article/54863-eng.htm

2. Fruh, S. M. (2017). Obesity: Risk factors, complications, and strategies for long-term weight management. Journal of the American Association of Nurse Practitioners, 29, S3-S13. http://doi.org/10.1002/2327-6924.12510

3. CPCSSN. (2019). Canadian Primary Care Sentinel Surveillance Network. Retrieved from http://cpcssn.ca

4. Rigobon, A. V., Birtwhistle, R., Khan, S., Barber, D., Biro, S., Morkem R., ... Williamson, T. (2015). Adult obesity prevelance in primary care users: An exploration using Canadian Primary Care Sentinel Survillance Network (CPCSSN) data. Candian Journal of Public Health, 106(5), 283-289. doi: 10.17269/CJPH.106.4508

5. Plourde, G. \& Prud'homme, D. (2012). Managing obesity in adults in primary care. Canadian Medical Association Journal, 184(9), 1039-44. doi: https://doi.org/10.1503/cmaj.111640

6. Statistics Canada. (2020). Measured adult body mass index (BMI) (World Health Organization classification), by age group and sex, Canada and provinces, Canadian Community Health Survey Nutrition 2020. Retrieved from: https://www150.statcan.gc.ca/t1/tbl1/en/tv.action?pid=1310079401

7. Waring, M. E., Roberts, M. B., Parker, D. R., \& Eaton, C. B. (2009). Documentation and management of overweight and obesity in primary care. Journal of the American Board of Family Medicine, 22(5), 544-552. doi: 10.3122/jabfm.2009.05.080173

8. Pedersen, A. B., Mikkelsen, E. M., Cronin-Fenton, D., Kristensen, N. R., Pham, T. M., Pedersen, L., \& Peetersen, E. (2017). Missing data and multiple imputation in clinical epidemiological research. Clinical Epidemiology, 9, 157-166. https://dx.doi.org/10.2147/CLEP.S129785

9. National Heart, Lung, and Blood Institute. (1998). Clinical guidelines on the identification, evaluation, and treatment of overweight and obesity in adults: executive summary. Expert Panel on the Identification, Evaluation, and Treatment of Overweight in Adults. American Journal of Clinical Nutrition, 68(4), 899-917.

10. Statistics Canada. (2017). Canada at a Glance 2017 Population 2017. Retrieved from: https://www150.statcan.gc.ca/n1/pub/12-581-x/2017000/pop-eng.htm

11. Sharma, A. M. \& Kushner, R. F. (2009). A proposed clinical staging system for obesity. International Journal of Obesity, 33(3), 289-95. doi: 10.1038/ijo.2009.2 


\section{Tables}

Table 1. Demographic characteristics.

\begin{tabular}{|l|l|l|l|l|}
\hline & Patients & $\begin{array}{l}\text { Waist } \\
\text { Circumference }\end{array}$ & $\begin{array}{l}\text { Body Mass } \\
\text { Index }\end{array}$ & $\begin{array}{l}\text { Waist Circumference \& Body } \\
\text { Mass Index }\end{array}$ \\
\hline $\begin{array}{l}\text { Number of } \\
\text { patients }\end{array}$ & $707,819^{1}$ & $81,268^{2}$ & $414,768^{3}$ & $79,701^{4}$ \\
\hline Female (\%) & $\begin{array}{l}392,181 \\
(55.4)\end{array}$ & $45,715(56.3)$ & $\begin{array}{l}236,706 \\
(57.1)\end{array}$ & $45,035(56.5)$ \\
\hline $\begin{array}{l}\text { Mean age (y) } \\
\text { (SD) }\end{array}$ & $\begin{array}{l}61.2 \\
(14.8)\end{array}$ & $61.6(13.3)$ & $60.8(13.6)$ & $61.6(13.2)$ \\
\hline Rural (\%) & $\begin{array}{l}132,464 \\
(18.7)\end{array}$ & $12,951(15.9)$ & $\begin{array}{l}75,922 \\
(18.3)\end{array}$ & $12,792(16.1)$ \\
\hline
\end{tabular}

ents with sex, residence postal code, and age data.

ast one waist circumference measurement

ast one body mass index measurement

ast one waist circumference measurement and at least one body mass index measurement

Table 2. Median body mass index $(\underline{\mathrm{n}=414}, \underline{768})$.

\begin{tabular}{|l|l|}
\hline & Frequency of patients (\%) \\
\hline Underweight (<18.5) & $4,656(1.1)$ \\
\hline Normal (18.5-24.9) & $112,674(27.2)$ \\
\hline Overweight (25.0-29.9) & $153,234(36.9)$ \\
\hline Class 1 Obese (30 - 34.9) & $86,661(20.9)$ \\
\hline Class 2 Obese (35 - 39.9) & $35,019(8.4)$ \\
\hline Class 3 Obese (>40.0) & $22,524(5.4)$ \\
\hline & \\
\hline & Median BMI; IQR \\
\hline All patients & $27.7 ; 7.5$ \\
\hline Males & $28.3 ; 6.4$ \\
\hline Females & $27.0 ; 8.2$ \\
\hline
\end{tabular}

Table 3. Median waist circumference $(\underline{\mathrm{n}=81}, \underline{268})$. 


\begin{tabular}{|l|l|}
\hline & Frequency of patients (\%) \\
\hline Male $>=102 \mathrm{~cm}$ & $16,991(47.8)$ \\
\hline Male $<101 \mathrm{~cm}$ & $18,562(52.2)$ \\
\hline Female $>=88 \mathrm{~cm}$ & $25,174(55.1)$ \\
\hline Female $<88 \mathrm{~cm}$ & $20,541(44.9)$ \\
\hline & \\
\hline & Median (cm) WC; IQR \\
\hline All patients & $95.0 ; 21.5$ \\
\hline Males & $100.0 ; 17.6$ \\
\hline Females & $90.0 ; 22.6$ \\
\hline
\end{tabular}

Table 4. Frequency of median WC category versus median BMI category.

\begin{tabular}{|c|c|c|c|c|c|c|c|}
\hline & $\begin{array}{l}\text { Males }>= \\
102 \mathrm{~cm}(\%) \\
\mathrm{n}=16,486\end{array}$ & $\begin{array}{l}\text { Males < } 101 \mathrm{~cm} \\
(\%) ; \mathrm{n}=18,180\end{array}$ & $\begin{array}{l}\text { Total } \\
\text { males; } \\
\mathrm{n}= \\
34,666 \\
\end{array}$ & $\begin{array}{l}\text { Female } \mathrm{n}>= \\
88 \mathrm{~cm}(\%) ; \\
\mathrm{n}=24,636\end{array}$ & $\begin{array}{l}\text { Female < } 88 \\
\mathrm{~cm}(\%) ; \\
\mathrm{n}=20,381\end{array}$ & $\begin{array}{l}\text { Total } \\
\text { females; } \\
n= \\
45,035\end{array}$ & $\begin{array}{l}\text { Total both } \\
\text { sexes; } \\
n=79,701\end{array}$ \\
\hline $\begin{array}{l}\text { Underweight } \\
(\mathrm{BMI}<18.5)\end{array}$ & $2(1.8)$ & 109 (98.2) & 111 & $9(1.7)$ & $521(98.3)$ & 530 & 641 \\
\hline $\begin{array}{l}\text { Normal (BMI: 18.5- } \\
24.9 \text { ) }\end{array}$ & $170(2.9)$ & $5,650(97.1)$ & 5,820 & $1,710(11.9)$ & $\begin{array}{l}12,548 \\
(88.0)\end{array}$ & 14,258 & 20,078 \\
\hline $\begin{array}{l}\text { Overweight (BMI } \\
25.0-29.9 \text { ) }\end{array}$ & $4,697(31.3)$ & 10,313 (68.7) & 15,010 & $8,841(60.3)$ & $5,822(39.7)$ & 14,663 & 29,673 \\
\hline $\begin{array}{l}\text { Class I Obese (BMI } \\
30.0-34.9)\end{array}$ & $7,354(81.2)$ & $1,706(18.8)$ & 9,060 & $7,568(88.7)$ & $950(11.1)$ & 8,536 & 17,596 \\
\hline $\begin{array}{l}\text { Class II Obese (35 - } \\
39.9)\end{array}$ & $2,925(91.9)$ & $257(8.1)$ & 3,182 & $3,845(92.3)$ & $319(7.7)$ & 4,164 & 7,346 \\
\hline $\begin{array}{l}\text { Class III Obese (> } \\
40.0 \text { ) }\end{array}$ & $1,338(90.2)$ & $145(9.8)$ & 1,483 & $2,663(92.3)$ & $221(7.7)$ & 2,884 & 4,367 \\
\hline
\end{tabular}

